$\stackrel{N}{N}$

Global Journals Inc.

is 5 है

\title{
Finned Electric Motor with Prescribed Heat Fluxand Influence of the Internal and External Heat Convection Coefficients on the Temperature of the Core
}

\author{
By Marcus V. F. Soares \& Élcio Nogueira \\ Rio de Janeiro State University
}

Abstract- One of a major objective is to analyze the effect of internal and external convection coefficients in the heat transfer generated by electric motors and characterize intervals of feasible values, in practical terms, for these coefficients. Another objective is to determine the motor core temperature, considering the environmental and operational conditions of the motor installation and the heat flux Q0 (fixed) in the fins. To achieve the objectives were developed analytical solutions for determining the temperature variations in the fins, performance and electric motor efficiency, considering heat flow constant at the base of the fins and the possible variations in temperature of surround media. The heat flux at the base of the fins, in this case, is the minimum necessary for satisfactory electric motor performance and the core temperature is within the safety range stipulated by the manufacturer. The obtained results characterize a range of possible values for the inner and outer heat transfer coefficients.

Keywords: finned electric motor; constant heat flow; efficiency; efficacy.

GJRE-A Classification: FOR Code: 091399

Strictly as per the compliance and regulations of:

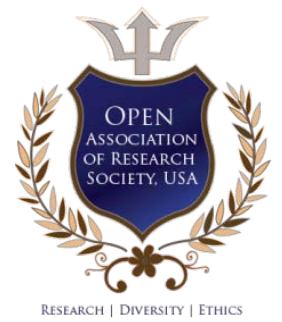

(c) 2019. Marcus V. F. Soares \& Élcio Nogueira. This is a research/review paper, distributed under the terms of the Creative Commons Attribution-Noncommercial 3.0 Unported License http://creativecommons.org/licenses/by-nc/3.0/), permitting all non commercial use, distribution, and reproduction in any medium, provided the original work is properly cited. 


\title{
Finned Electric Motor with Prescribed Heat Fluxand Influence of the Internal and External Heat Convection Coefficients on the Temperature of the Core
}

\author{
Marcus V. F. Soares ${ }^{\alpha}$ \& Élcio Nogueira ${ }^{\sigma}$
}

\begin{abstract}
One of a major objective is to analyze the effect of internal and external convection coefficients in the heat transfer generated by electric motors and characterize intervals of feasible values, in practical terms, for these coefficients. Another objective is to determine the motor core temperature, considering the environmental and operational conditions of the motor installation and the heat flux $Q_{0}$ (fixed) in the fins. To achieve the objectives were developed analytical solutions for determining the temperature variations in the fins, performance and electric motor efficiency, considering heat flow constant at the base of the fins and the possible variations in temperature of surround media. The heat flux at the base of the fins, in this case, is the minimum necessary for satisfactory electric motor performance and the core temperature is within the safety range stipulated by the manufacturer. The obtained results characterize a range of possible values for the inner and outer heat transfer coefficients. These values guarantee the lowest value for the heat transfer rate required for efficient heat removal at the given environmental temperature.
\end{abstract}

Keywords: finned electric motor; constant heat flow; efficiency; efficacy.

\section{INTRODUCTION}

T he electric motor is responsible for the transformation of electric energy into mechanical energy, which is the main end-use of electric energy in industries in general, and its wide use in this sector is due to its simple construction and wide versatility in applying loads.

Factors that allow electric motors to lose up to $4 \%$ of their performance over their lifetime are improper installations, lack of regular maintenance, cleanliness and quality lubrication (Cardoso et. Al., 2009). Therefore, overheating the electric motor and consequently burning it is a problem for maintenance personnel, since heat produced by the electric motor must be dissipated efficiently, avoiding overheating and consequent burning. The high temperatures of the installation environment and the inefficient heat dissipation

Author $\alpha$ : Graduate in Mechanical Engineer at the University Center of Volta Redonda - UniFOA, Brazil. Rio de Janeiro State University.

e-mail: engemec.marcusvinicius@gmail.com

Author o: Assistant Professor at the Faculty of Technology of the State University of Rio de Janeiro - FAT/UERJ, Brazil.

e-mail: elcionogueira@hotmail.com generated by the difference in net power supplied by the motor and power absorbed in the line is the main cause of overheating (Santos, Rafael Simões, 2011).

Fins or the extended surfaces are extensively used in engineering applications to increase the heat transfer efficiency of surfaces, and are of vital importance in the design of heat exchange devices in different fields of applications in order to provide an enhanced heat transfer effect through an increase in the total heat exchange area (Campo, A.; Kundu, B.,2017), (Incropera, Frank P. Et Al., 2008), (Santos, T. A. M., 2017). Once the temperature distribution through the fin is known, the heat transfer rate and the efficiency can be readily determined.

In electric motors, it is common to use extended surfaces, which increase the exchange area as a mechanism for heat transfer optimization. In fact, an important industrial application of fins occurs in electric motors and are of vital importance in the industry as they are used in machines of all types, including, for example, computer ventilation and other electronic equipment. A well-dimensioned finned ventilation system can contribute to energy savings.

The heat dissipation is directly associated with efficient ventilation, the temperature difference between the engine housing surface and the medium (in this case, the air surrounding the engine), the total heat exchange area of the engine housing and of extended surfaces (fins). Important feature is the geometry of the fins, as they have a great influence on the area available for exchange and, in order to heat transfer as good as possible, the construction material of these fins must have high thermal conductivity, such as aluminum and copper (Duarte, Denise Freire; Novais, Ariane Silva; Nogueira, Élcio, 2012), (Novais, Ariane; Chagas, R. D. F.; Nogueira, Élcio, 2014), (Marcus Vinicius Ferreira Soares, 2015), (Voigdlener, Thiago, 2004).

Ventilation depends directly on the internal and external convection heat transfer to which the motor is subjected. This dependence is because the heat exchange occurs between a moving fluid (air) and the motor surface (housing), which are at different temperatures. The air moves due to the internal and 
external convection process causing a random molecular displacement on the surface. According to Ordenes (2008), the convection coefficient is a proportionality constant that considers several factors, including surface geometry and the nature of the flow.

Novais and Comitra (2014) showed that one of the factors that contribute to burning is the thermal resistance that exists between the housing and the motor core. According to Moreira (2012), besides the convection acting in the region outside the motor housing, and its respective convection coefficient, there is also the convection in the internal region and the resistance associated with the conduction process that occurs in the air layer, between the core and the motor housing.

The contact interface between the motor wall and its insulation is promoted by a mechanical union that generates a thermal resistance due to imperfect contact, resulting from small roughness and undulation. In this region, conduction occurs at the contact points and conduction through the trapped fluids in the interstices of roughness and undulation. However, it is important to note that some motors do not use this contact interface between the motor wall and its insulation, being air the only element that serves as thermal resistance between the motor core and the housing.

Thus, we have to determine two convection coefficients, one of them referring to the external region and the other to the internal part of the motor housing, the latter is also dependent on the microscopic imperfections on the surfaces and the contact pressure of the materials, the fluid contained in the interstices, of the applied oxide film and the metallic shim involved.
This latter convection coefficient is undoubtedly the most complex of the two processes and the most difficult to obtain experimentally.

Although the internal resistance is crucial for the correct motor thermal sizing, the usual theoretical models still consider the temperature at the fin base attached to the motor housing equal to the motor core temperature.

In Table 1 below, some physical and geometrical characteristics of the engine.

Table 1: Engine Data

\begin{tabular}{l|c}
\hline Power & $1 \mathrm{cv}$ \\
\hline Number of Poles & 4 \\
\hline Motor Outer Diameter & $139,60 \mathrm{~mm}$ \\
\hline Engine Width & $130,13 \mathrm{~mm}$ \\
\hline Number of Fins & 32 \\
\hline Fin Base Width & $5,84 \mathrm{~mm}$ \\
\hline Fin Height & $17,00 \mathrm{~mm}$ \\
\hline Maximum Ambient Temperature & $40^{\circ} \mathrm{C}$ \\
\hline
\end{tabular}

\section{Theoretical Analysis}

Analytical solutions for temperature profiles were developed considering constant heat flux in the fins, and constant thermo physical properties. Variations were also simulated between the motor housing construction materials: cast iron and aluminum.

In this context we have the Ordinary Differential Equation (E.D.O.) of the rectangular profile fin, described by the equation below:

$$
\frac{d^{2} T(r)}{d r^{2}}=\frac{h \cdot A_{l}}{k \cdot V}\left[T(r)-T_{\infty}\right]
$$

at where: $A_{l}=P_{b} \cdot \operatorname{LeV}=A_{b} \cdot L$

$$
\begin{aligned}
\frac{d^{2} T(r)}{d r^{2}} & =\frac{h \cdot P_{b}}{k \cdot A_{b}}\left[T(r)-T_{\infty}\right] \\
\theta(r) & =T(r)-T_{\infty} \\
\frac{d^{2} \theta(r)}{d r^{2}} & =\frac{h \cdot P_{b}}{k \cdot A_{b}} \theta(r)
\end{aligned}
$$

making $m^{2}=\frac{h \cdot P_{b}}{k \cdot A_{b}}$ and substituting in equation (3) we have:

$$
\begin{gathered}
\frac{d^{2} \theta(r)}{d r^{2}}=m^{2} \cdot \theta(r) \\
a s m^{2}=\frac{h \cdot P_{b}}{k \cdot A_{b}} \rightarrow m=\sqrt{\frac{h \cdot P_{b}}{k \cdot A_{b}}}
\end{gathered}
$$

Whose E.D.O general solution is:

$$
\theta(r)=C_{1} \cdot \cosh (m r)+C_{2} \cdot \operatorname{senh}(m r)
$$


1st boundary condition: $r=0$

$$
-k \cdot \frac{d \theta}{d r}=Q_{0}
$$

2nd boundary condition: $r=\mathrm{L}$

At where

$$
-k \cdot \frac{d \theta}{d r}=h_{2} \cdot \theta_{L}
$$

$$
\begin{gathered}
\theta_{L}=\theta(L)=T(L)-T_{\infty} \\
\frac{d \theta}{d r}=C_{1} \cdot m \cdot \operatorname{senh}(m L)+C_{2} \cdot m \cdot \cosh (m L)
\end{gathered}
$$

From the first boundary condition $(r=0)$, we must:

$$
\begin{gathered}
-k \cdot\left[C_{1} \cdot m \cdot \operatorname{senh}(m \cdot 0)+C_{2} \cdot m \cdot \cosh (m \cdot 0)\right]=Q_{0} \\
\text { as } \operatorname{senh}(0)=0 \text { e } \cosh (0)=1, \text { we have: } \\
-k \cdot\left[C_{2} \cdot m\right]=Q_{0} \\
C_{2}=-\frac{Q_{0}}{. k m}
\end{gathered}
$$

From the 2nd boundary condition $(r=L)$, we must:

$$
\begin{gathered}
-k \cdot\left[C_{1} \cdot m \cdot \operatorname{senh}(m L)+C_{2} \cdot m \cdot \cosh (m L)=h_{2} \cdot\left[C_{1} \cdot \cosh (m L)+C_{2} \cdot \operatorname{senh}(m L)\right]\right. \\
-\frac{k}{h_{2}} \cdot C_{1} \cdot m \cdot \operatorname{senh}(m L)-\frac{k}{h_{2}} C_{2} \cdot m \cdot \cosh (m L)=C_{1} \cdot \cosh (m L)+C_{2} \cdot \operatorname{senh}(m L) \\
-C_{1}\left[\frac{k \cdot m}{h_{2}} \cdot \operatorname{senh}(m L)+\cosh (m L)\right]=C_{2}\left[\frac{k \cdot m}{h_{2}} \cdot \cosh (m L)+\operatorname{senh}(m L)\right] \\
C_{1}=-C_{2} \cdot \frac{\left[\frac{k \cdot m}{h_{2}} \cdot \cosh (m L)+\operatorname{senh}(m L)\right]}{\left[\frac{k \cdot m}{h_{2}} \cdot \operatorname{senh}(m L)+\cosh (m L)\right]} \\
C_{1}=\frac{Q_{0}}{k \cdot m} \cdot \frac{\left[\frac{k \cdot m}{h_{2}} \cdot \cosh (m L)+\operatorname{senh}(m L)\right]}{\left[\frac{k \cdot m}{h_{2}} \cdot \operatorname{senh}(m L)+\cosh (m L)\right]} \\
Q_{0}=0,25 \cdot\left[\frac{\left(\frac{750}{32}\right)}{A}\right]
\end{gathered}
$$

$Q_{0}$ is the flow prescribed on the fins and $A$ is the area of the fin. Note that $750 \mathrm{~W}$ is the engine power. The calculated value of $Q_{0}$ for the motor studied is $7709.7 \mathrm{~W} / \mathrm{m}^{2}$.

To determine the motor core temperature, we have:

$$
\begin{gathered}
\dot{q}=\frac{T_{M}-T_{b}}{\frac{1}{h_{1} A}+\frac{\ln \left(\mathrm{D}_{2} / \mathrm{D}_{1}\right)}{2 \pi K L}} \\
A=\pi \cdot D_{1} \cdot L \quad \text { e } \quad D_{1}=D_{2}-2 \cdot E_{0}
\end{gathered}
$$

$E_{0}=$ Motor wall thickness 


$$
\begin{gathered}
\frac{\dot{q}}{A}=\frac{T_{M}-T_{b}}{\frac{1}{h_{1}}+\frac{\mathrm{A} \cdot \ln \left(D_{2} / D_{1}\right)}{2 \pi K L}} \\
\frac{\dot{q}}{A}=Q_{0}=\frac{T_{M}-T_{b}}{\frac{1}{h_{1}}+\frac{D_{1} \cdot \ln \left(D_{2} / D_{1}\right)}{2 K}} \\
Q_{0} \cdot\left[\frac{1}{h_{1}}+\frac{D_{1} \cdot \ln \left(D_{2} / D_{1}\right)}{2 K}\right]=T_{M}-T_{b} \\
T_{M}=T_{b}+Q_{0} \cdot\left[\frac{1}{h_{1}}+\frac{D_{1} \cdot \ln \left(D_{2} / D_{1}\right)}{2 K}\right]
\end{gathered}
$$

where $T_{b}$ is the temperature at the base of the fin, which depends on the operating conditions, i.e. external temperature $T_{\infty}$ and external convection coefficient $h_{2}$.

\section{Results And Discussion}

The Table 2 shows the numerical values for motor core temperature with $\mathrm{h}_{2}=1000 \mathrm{~W} /\left(\mathrm{m}^{2} .{ }^{\circ} \mathrm{C}\right)$ and $h_{1}$ e $T_{\infty}$ as variables.
We analyzed the temperatures ambient strictly below $45{ }^{\circ} \mathrm{C}$ for cast iron and aluminum materials. The data in Table 2 and Figure 1, related to the internal and external heat transfer coefficients, show that under the best possible condition $\left[\mathrm{h} 2=1000 \mathrm{~W} /\left(\mathrm{m}^{2} .{ }^{\circ} \mathrm{C}\right)\right]$, there is no considerable difference between the analyzed materials.

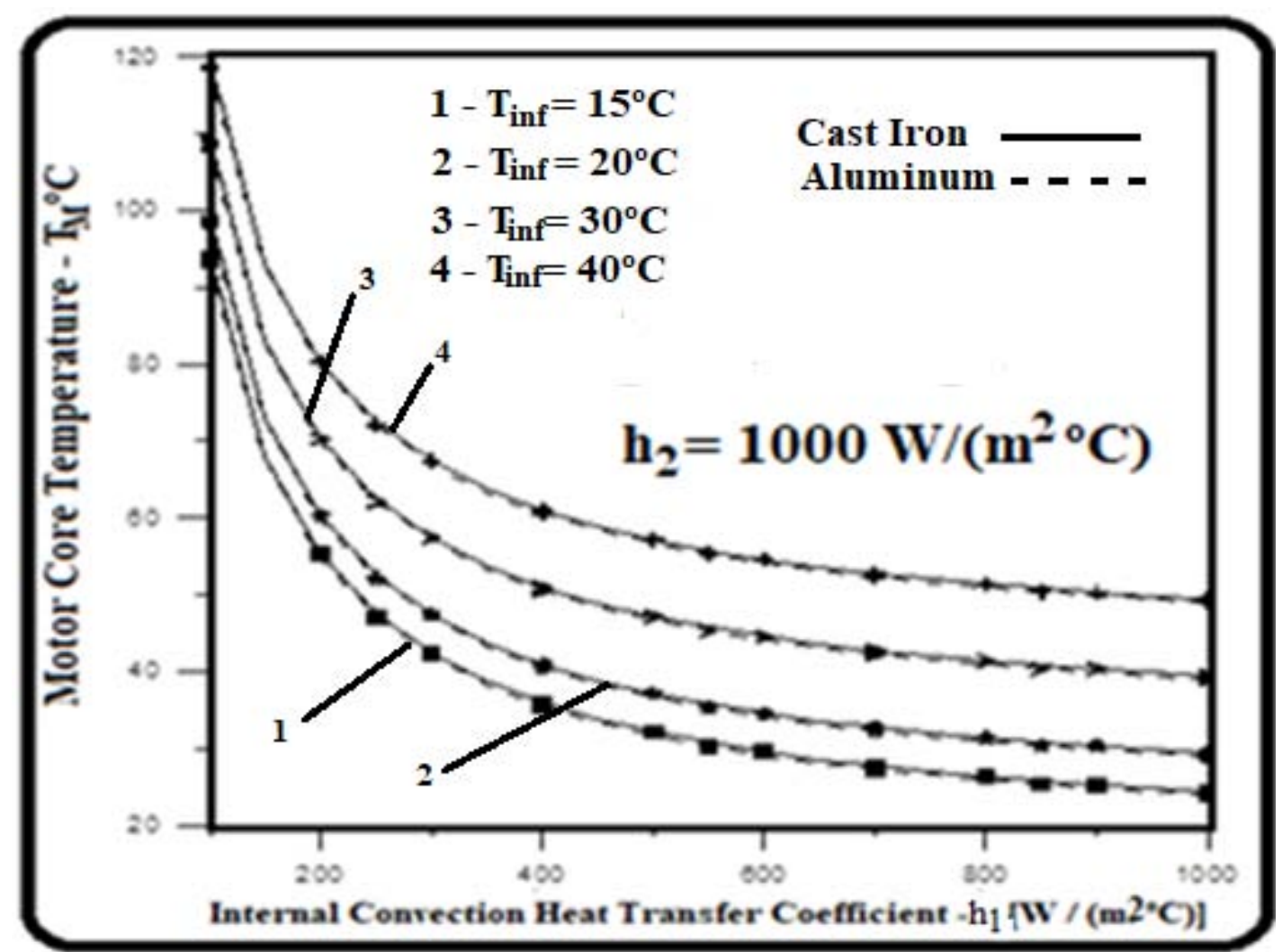

Authors

Figure 1: Motor Core Temperature $-h_{1} \times T_{M}$ 
Table 2: Motor Core Temperature $\left(T_{M}\right)$ versus Internal Convection Coefficient $\left(h_{1}\right) h_{2}=1000 \mathrm{~W} /\left(\mathrm{m}^{2}{ }^{\circ} \mathrm{C}\right)$

\begin{tabular}{|c|c|c|c|c|c|c|c|c|}
\hline \multirow{2}{*}{$\begin{array}{c}\mathrm{h} 1 \\
\mathrm{~W} /\left(\mathrm{m}^{2^{\circ}} \mathrm{C}\right)\end{array}$} & $T_{\infty}=15$ & ${ }^{\circ} \mathrm{C}$ & $T_{\infty}=20$ & ${ }^{\circ} \mathrm{C}$ & $T_{\infty}=30$ & ${ }^{\circ} \mathrm{C}$ & $T_{\infty}=40$ & ${ }^{\circ} \mathrm{C}$ \\
\hline & $\begin{array}{l}\text { Iron } \\
\text { Cast }\end{array}$ & $\mathrm{Al}$ & $\begin{array}{l}\text { Iron } \\
\text { Cast }\end{array}$ & Al & $\begin{array}{l}\text { Iron } \\
\text { Cast }\end{array}$ & Al & $\begin{array}{l}\text { Iron } \\
\text { Cast }\end{array}$ & Al \\
\hline 100 & 93,86 & 93,40 & 98,86 & 98,40 & 108,86 & 108,40 & 118,86 & 118,40 \\
\hline 150 & 68,16 & 67,70 & 73,16 & 72,70 & 83,16 & 82,70 & 93,16 & 92,70 \\
\hline 200 & 55,31 & 54,85 & 60,31 & 59,85 & 70,31 & 69,85 & 80,31 & 79,85 \\
\hline 250 & 47,60 & 47,14 & 52,60 & 52,14 & 62,60 & 62,14 & 72,60 & 72,14 \\
\hline 300 & 42,46 & 42,00 & 47,46 & 47,00 & 57,46 & 57,00 & 67,46 & 67,00 \\
\hline 350 & 38,79 & 38,33 & 43,79 & 43,33 & 53,79 & 53,33 & 63,79 & 63,33 \\
\hline 400 & 36,04 & 35,58 & 41,04 & 40,58 & 51,04 & 50,58 & 61,04 & 60,58 \\
\hline 450 & 33,90 & 33,43 & 38,89 & 38,43 & 48,89 & 48,43 & 58,89 & 58,43 \\
\hline 500 & 32,18 & 31,72 & 37,18 & 36,72 & 47,18 & 46,72 & 57,18 & 56,72 \\
\hline 550 & 30,78 & 30,32 & 35,78 & 35,32 & 45,78 & 45,32 & 55,78 & 55,32 \\
\hline 600 & 29,61 & 29,15 & 34,61 & 34,15 & 44,61 & 44,15 & 54,61 & 54,15 \\
\hline 650 & 28,62 & 28,16 & 33,62 & 33,16 & 43,62 & 43,16 & 53,62 & 53,16 \\
\hline 700 & 27,78 & 27,32 & 32,78 & 32,32 & 42,78 & 42,32 & 52,78 & 52,32 \\
\hline 750 & 27,04 & 26,58 & 32,04 & 31,58 & 42,04 & 41,58 & 52,04 & 51,58 \\
\hline 800 & 26,40 & 25,94 & 31,40 & 30,94 & 41,40 & 40,94 & 51,40 & 50,94 \\
\hline 850 & 25,83 & 25,37 & 30,83 & 30,37 & 40,83 & 40,37 & 50,83 & 50,37 \\
\hline 900 & 25,33 & 24,87 & 30,33 & 29,87 & 40,33 & 39,87 & 50,33 & 49,87 \\
\hline 950 & 24,88 & 24,42 & 29,88 & 29,42 & 39,88 & 39,42 & 49,88 & 49,42 \\
\hline 1000 & 24,47 & 24,01 & 29,47 & 29,01 & 39,47 & 39,01 & 49,47 & 49,01 \\
\hline
\end{tabular}

For analysis purposes, a maximum engine core working temperature of $98^{\circ} \mathrm{C}$ is assumed. The manufacturer sets the maximum operating temperature equal to $120^{\circ} \mathrm{C}$.

Analyzing Figure 2, for the external temperature of $40^{\circ} \mathrm{C}$, we have that, for Cast Iron the motor to work in the acceptable temperature range, the value of $h_{2}$ must be greater than or equal to $200 \mathrm{~W} /\left(\mathrm{m}^{2} .{ }^{\circ} \mathrm{C}\right)$.

For the value of $h_{1}=200 \mathrm{~W} /\left(\mathrm{m}^{2} .{ }^{\circ} \mathrm{C}\right)$, shown in Figure 3 , the motor works at the limit established in the research and we can conclude that the motor works properly for values of $h_{1}$ above $200 \mathrm{~W} /\left(\mathrm{m}^{2} .{ }^{\circ} \mathrm{C}\right)$.

Analyzing Figure 4, for the external temperature of $40^{\circ} \mathrm{C}$, we arrive at the following conclusions: for $h_{1}=$ $100 \mathrm{~W} /\left(\mathrm{m}^{2} .{ }^{\circ} \mathrm{C}\right)$ the motor temperature is equal to $128.61^{\circ} \mathrm{C}$, which goes beyond the limit value. From research of $98^{\circ} \mathrm{C}$. In the same Figure 4 , for $h_{1}=200 \mathrm{~W} /$ $\left(\mathrm{m}^{2} .{ }^{\circ} \mathrm{C}\right)$ the motor temperature is equal to $90.06{ }^{\circ} \mathrm{C}$, below the search limit value. The value of $h_{1}=200 \mathrm{~W} /$ $\left(\mathrm{m}^{2} .{ }^{\circ} \mathrm{C}\right)$ is feasible and achievable in natural ventilation. 


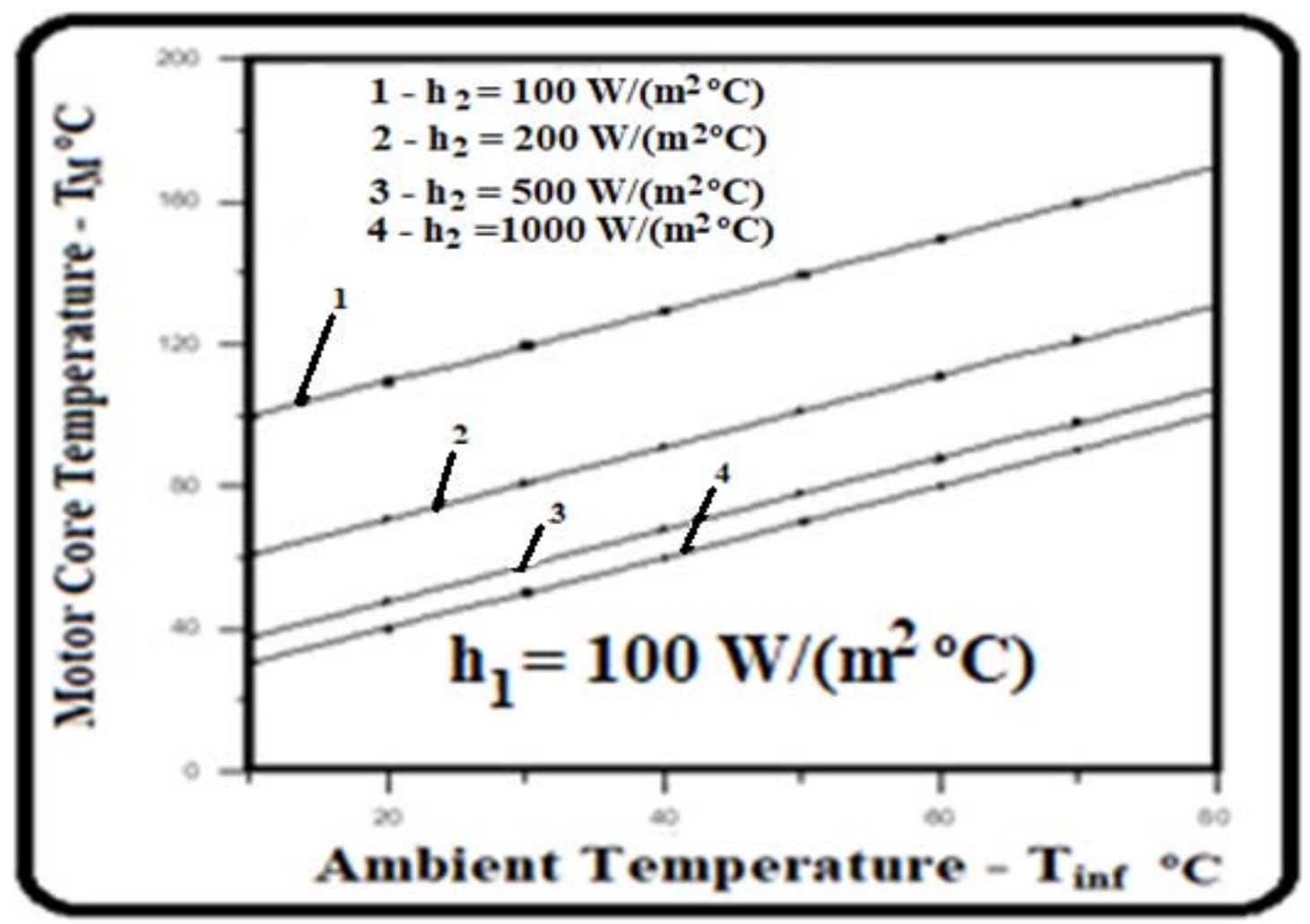

Authors

Figure 2: Motor Core Temperature $-T_{\text {inf }} \times T_{M}$

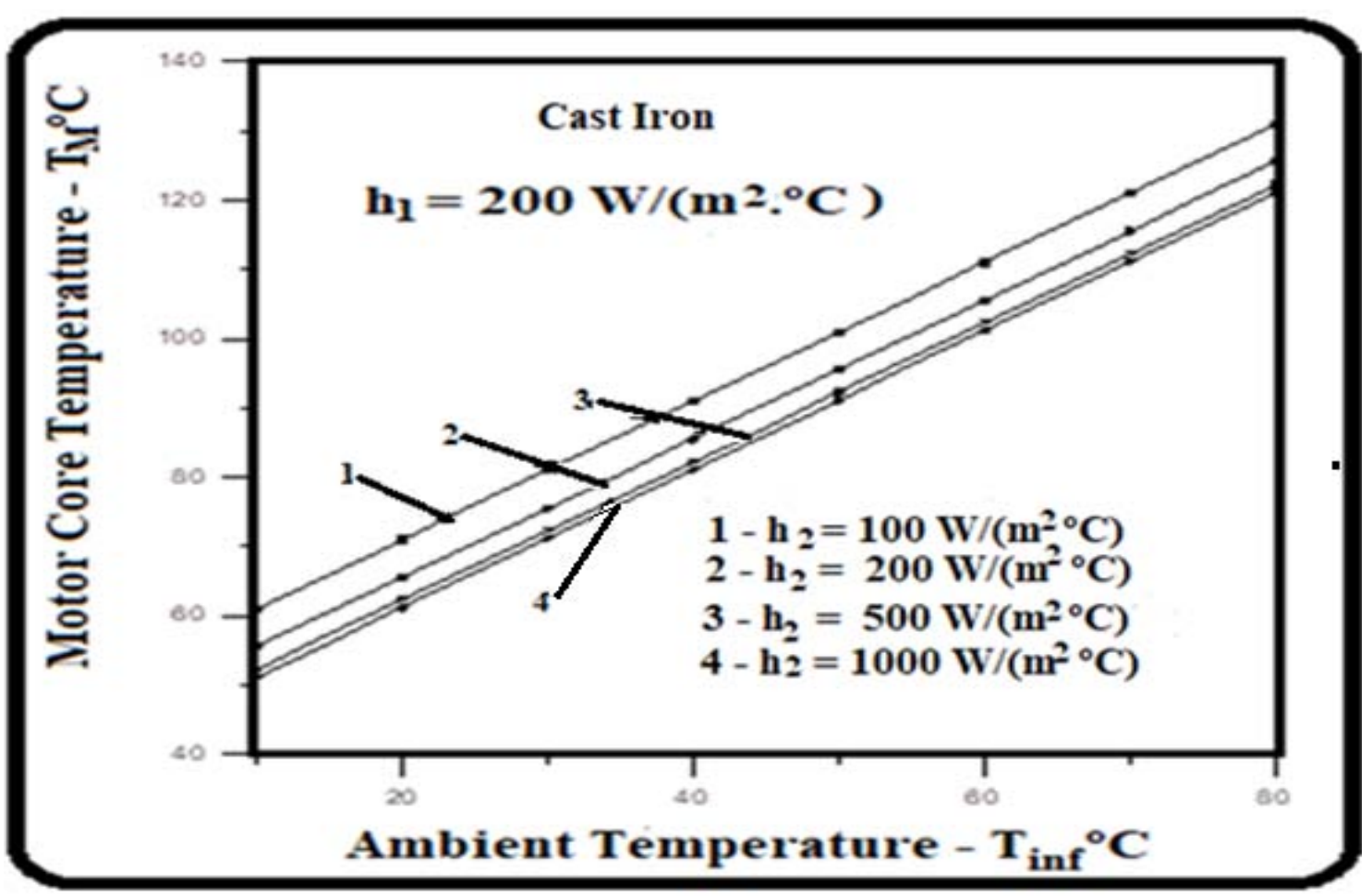

Authors

Figure 3: Motor Core Temperature $-T_{\text {inf }} \times T_{M}$ 


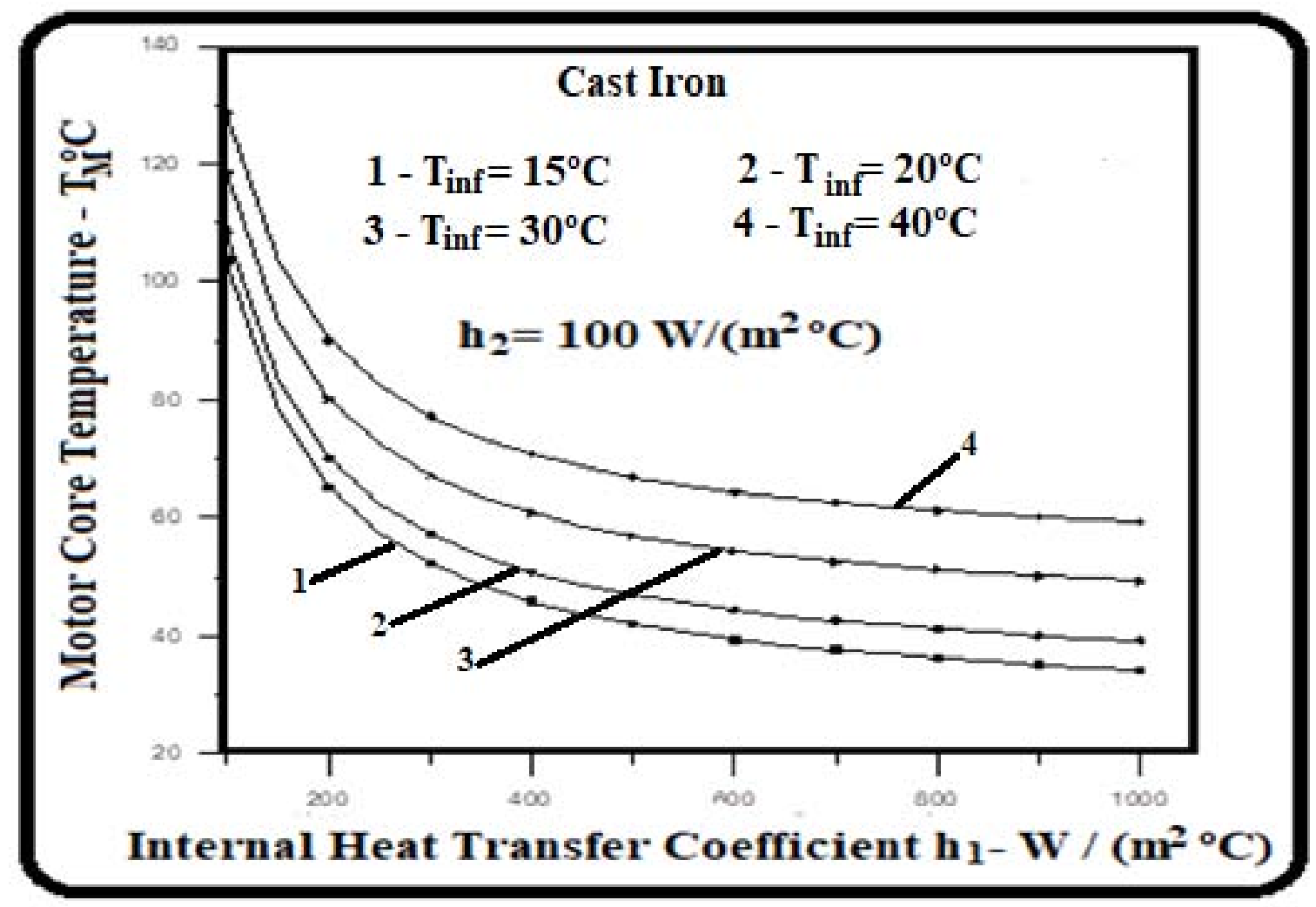

Authors

Figure 4: Motor Core Temperature $-h_{1} \times T_{M}$

Looking at Figure 5 for the external temperature of $40^{\circ} \mathrm{C}$, we arrive at the following conclusions: for $\mathrm{h}_{1}=$ $150 \mathrm{~W} /\left(\mathrm{m}^{2} .{ }^{\circ} \mathrm{C}\right)$ the motor temperature is equal to $97.48^{\circ} \mathrm{C}$, very close to $98^{\circ} \mathrm{C}$, but already below search limit. In the same Figure 5 , for $h_{1}=200 \mathrm{~W} /\left(\mathrm{m}^{2}{ }^{\circ} \mathrm{C}\right)$ the motor temperature is $84.63^{\circ} \mathrm{C}$, below the search limit value.

Figure 6, is the graph constructed from the data generated for engine efficiency. Note how aluminum results are far superior to cast iron.

$$
\eta_{\text {motor }}=\frac{Q_{0}}{h_{2} \cdot\left[A_{L}+\left(A_{\text {Motor }}-32 \cdot A_{b}\right)\right] \cdot\left(T_{b}-T_{\infty}\right)}
$$

Another parameter to be analyzed is the fin and non-fin motor heat exchange. The efficacy effectiveness of the engine, which is the ratio between formulagiven by:

$$
\varepsilon_{\text {motor }}=\frac{Q_{0}}{h_{2} \cdot A_{\text {Motor }} \cdot\left(T_{b}-T_{\infty}\right)}
$$

Again, Figure 7, demonstrates that the results for aluminum are much higher than those obtained by cast iron.

Looking at Figure 7, we can conclude that a reasonable effectiveness value for a fin of 2.5 is achieved when $h_{2}$ is near $400 \mathrm{~W} /\left(\mathrm{m}^{2} .{ }^{\circ} \mathrm{C}\right)$ for cast iron. 


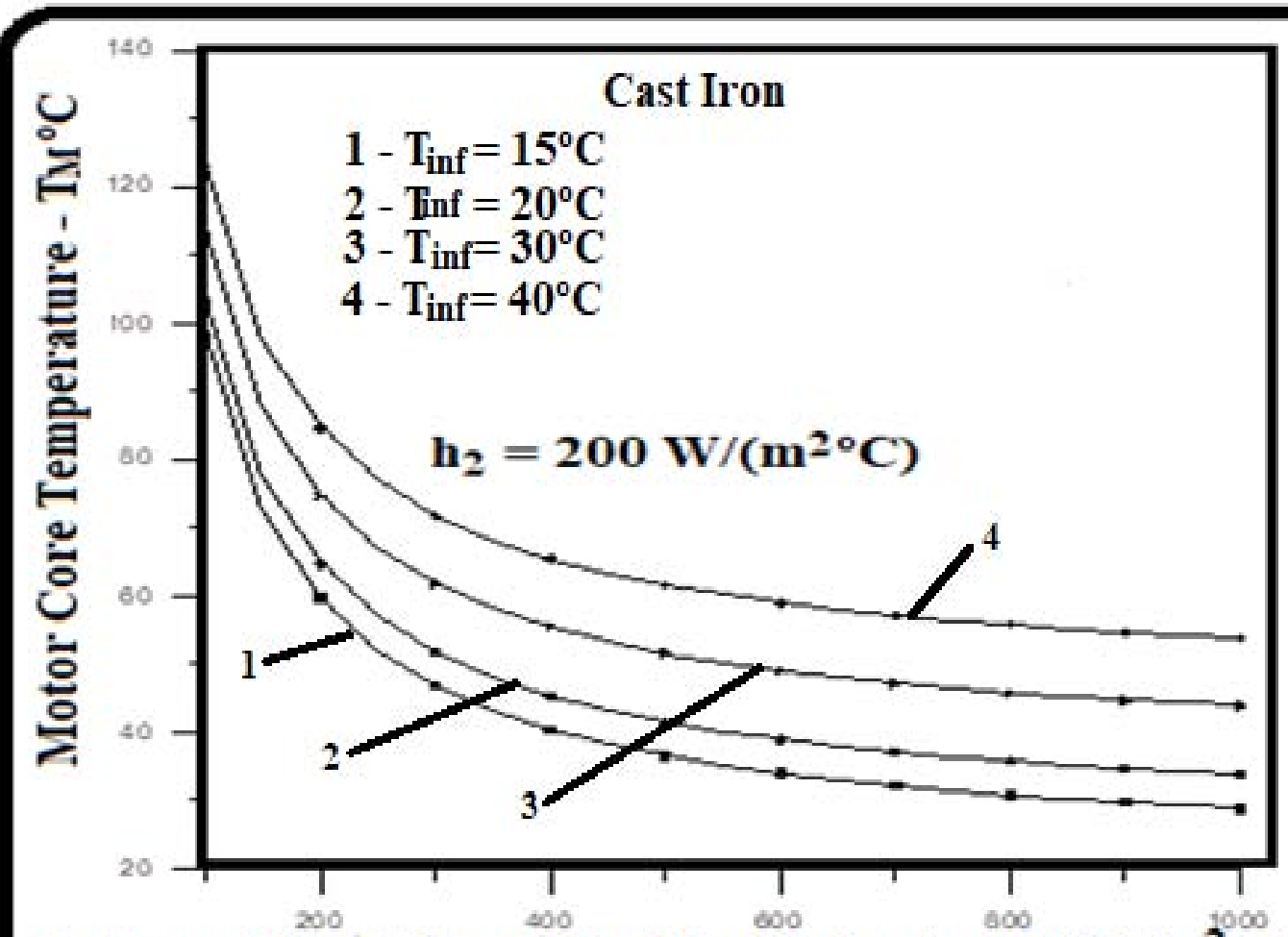

Internal Heat Transfer Coefficient $-h_{1} W /\left(m^{2 \infty} C\right)$

Authors

Figure 5: Motor Core Temperature $-h_{1} \times T_{M}$

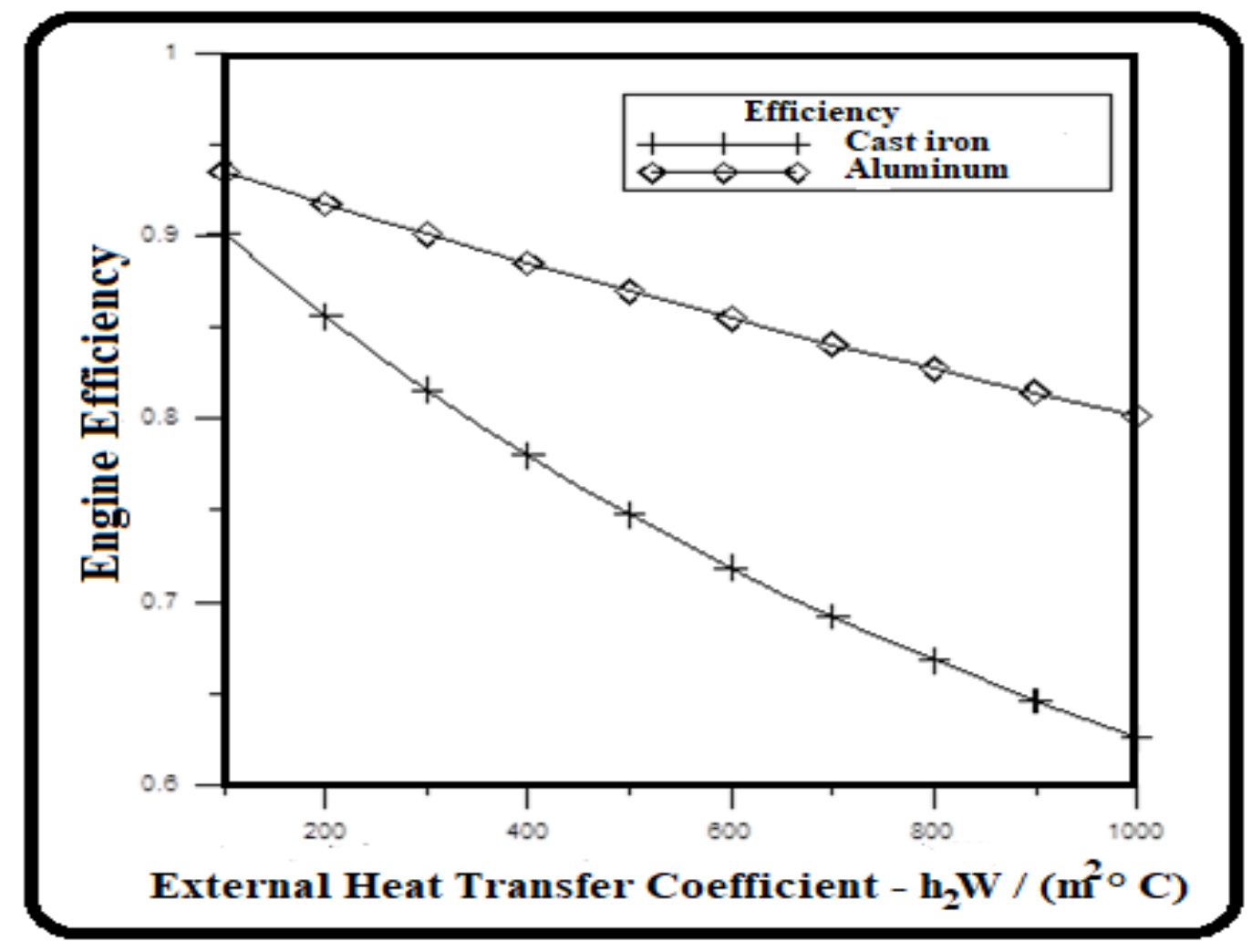

Authors

Figure 6: Engine Efficiency 


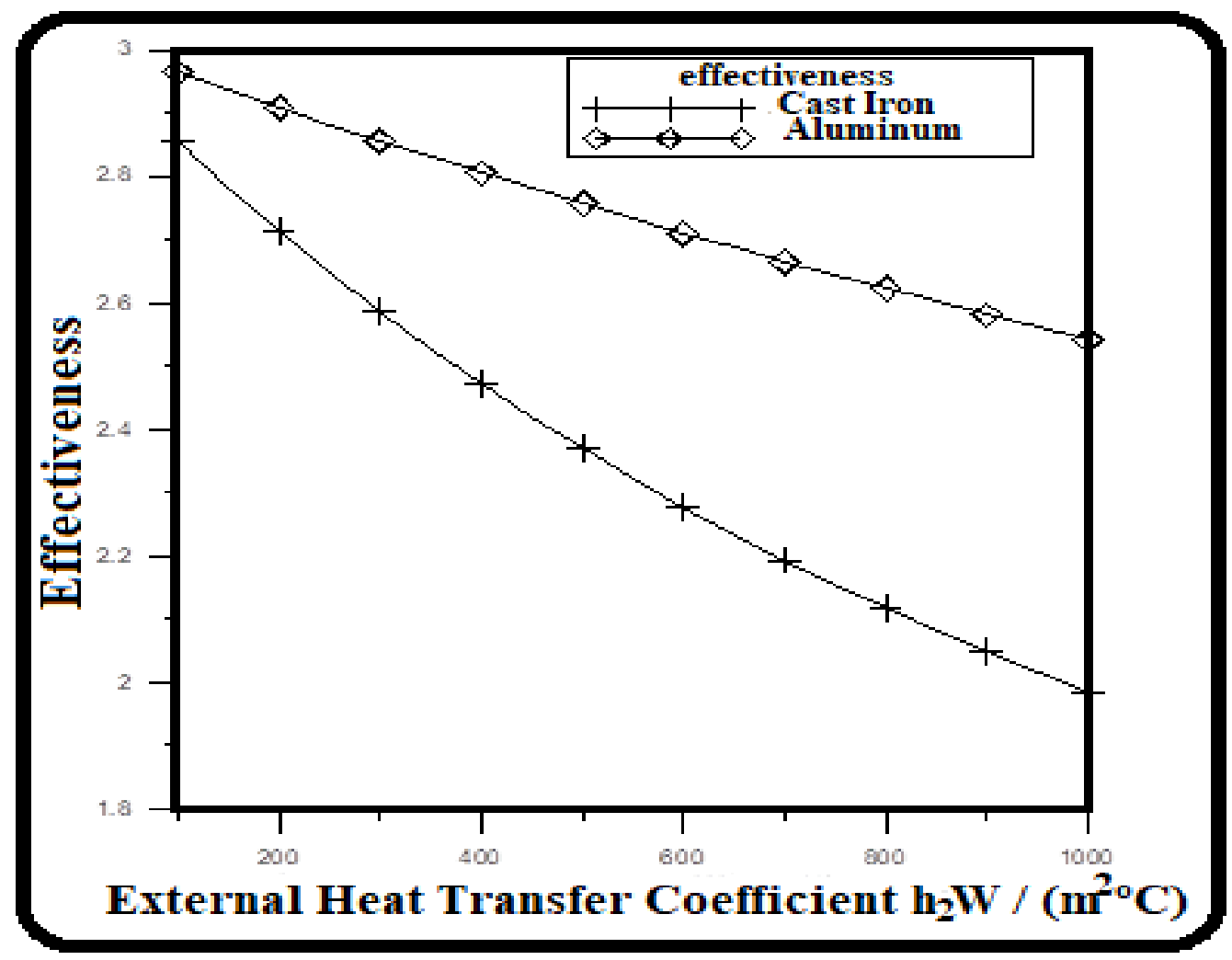

Authors

Figure 7: Engine Effectiveness

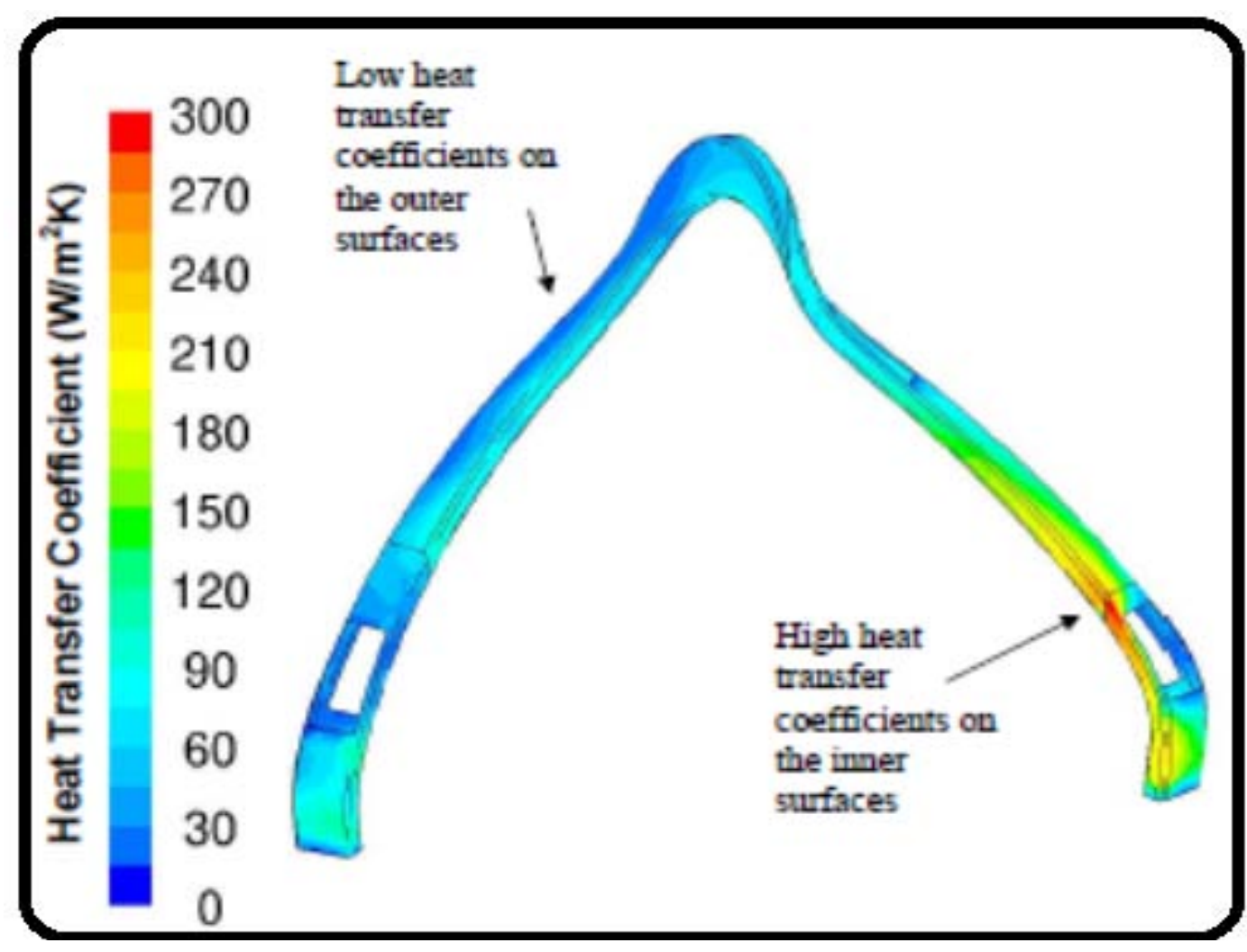

Figure 8: Contour for Local Heat Transfer Coefficient Beng, Christopher Micallef(2006) 
Based on the results observed above, and in the graphs of efficiency and effectiveness, we conclude that for any values of $h_{1} \geq 200 \mathrm{~W} /\left(\mathrm{m}^{2}{ }^{\circ}{ }^{\circ} \mathrm{C}\right)$ and $\mathrm{h}_{2} \geq$ $200 \mathrm{~W} /\left(\mathrm{m}^{2} \cdot{ }^{\circ} \mathrm{C}\right)$ the engine temperature will have a satisfactory value. However, the values of $h_{1}$ and $h_{2}$ are physically limited. For $h_{1}$ to assume values greater than $400 \mathrm{~W} /\left(\mathrm{m}^{2}{ }^{\circ} \mathrm{C}\right)$, forced ventilation must be used with the aid of a fan inside the engine or by drilling holes in the housing to increase natural ventilation. In addition, for $h_{2}$ to assume values greater than $400 \mathrm{~W} /\left(\mathrm{m}^{2} .{ }^{\circ} \mathrm{C}\right)$, ventilation must be increased in the environment where the engine is installed, which would generate more costs for the company.

The above results are consistent with the results presented and experimentally confirmed by Micallef (2006), Figure 8 above, in his doctoral dissertation entitled "End Winding Cooling in Electric Machines". In his studies, using experimental and numerical method CFD - Computation Fluid Dynamic, the author applied three distinct turbulence models, and the results showed that the closer to the motor core, the higher the heat transfer coefficient by convection acting on the internal surfaces.

The measured internal coefficient assumed values close to $300 \mathrm{~W} /\left(\mathrm{m}^{2} . \mathrm{K}\right)$, a value that is included in the working range proposed by this study.

\section{Conclusion}

The motor core temperature was computationally simulated by varying the internal $\left(h_{1}\right)$ and external $\left(h_{2}\right)$ convection heat transfer coefficients and the ambient temperature. The results demonstrated two things: the importance of the internal heat transfer coefficients and their physical limitations.

Regarding the heat transfer coefficients, we can conclude that the values of $h_{1}$ and $h_{2}$ cannot be treated separately. For very low $h_{1}$ and $h_{2}$ values the fins tend to be at the same temperature as the outside temperature, so there is no efficient heat exchange, overheating the engine. For very high $h_{1}$ values, which is physically impossible to obtain, we have that the fin base tends to stay with the motor core temperature, with is the usually conditions generally used by the one-dimension and two-dimension fin models.

We conclude that for any values of $h_{1} \geq 200 \mathrm{~W} /$ $\left(m^{2} .{ }^{\circ} \mathrm{C}\right)$ and $h_{2} \geq 200 \mathrm{~W} /\left(\mathrm{m}^{2} .{ }^{\circ} \mathrm{C}\right)$ the motor temperature will have a satisfactory value. However, as already mentioned, the values of $h_{1}$ and $h_{2}$ are physically limited. For $h_{1}$ to assume values greater than $400 \mathrm{~W} /$ $\left(\mathrm{m}^{2} .{ }^{\circ} \mathrm{C}\right)$, which is already a critical value to obtain for mechanical reasons, it is necessary to use forced ventilation inside the engine or drill holes in the housing to increase nature ventilation. The same reasoning can be used for the external coefficient $h_{2}$, which would entail a higher cost to the company, as it would be necessary to increase ventilation at the engine installation site.

Thus, the ranges, $200 \leq h_{1} \leq 300$ and $200 \leq h_{2}$ $\leq 400$, are the limit values that guarantee the lowest value for the heat transfer rate required for efficient heat removal. Any values above these will increase the transfer rate and consequently decrease the motor core temperature, however, considering the difficulties of achieving these values in practical terms.

\section{REFERENCES RÉFÉRENCES REFERENCIAS}

1. Beng, Christopher Micallef. "End Winding Cooling in Electric Machines". University of Nottingham, September 2006.

2. Campo, A.; Kundu, B. "Exact Analytic Heat Transfer from an Annular Fin with Stepped Rectangular Profile". American Journal of Heat and Mass Transfer, Vol. 4 No. 4, pp. 146-155 doi:10.7726/ajhmt.2017.1013, 2017.

3. Cardoso, Rafael Balbino et al. "Energy Savings Assessment Attributed to Energy Labeling Actions in Induction Motors In Brazil". BrazilianJournal of Energy, Vol.15, N. 1.1 Sem. 29-47, 2009.

4. Duarte, Denise Freire; Novais, Ariane Silva; Nogueira, Élcio. "Rectangular Profile Fin Analytical Solution: Comparison of Thermal Performance Between Aluminum and Cast Iron in Electric Motors". Uni FOA, Volta Redonda, Brazil, 2012.

5. Incropera, Frank P. et al. "Heat and Mass Transfer Fundamentals". 6th ed. Riode Janeiro, Brazil, LTC, 644 pg, 2008.

6. Marcus Vinicius Ferreira Soares. "Analysis of the Influence of Convection Heat Transfer Coefficient on the Temperature of the Finned Electric Motor Core with Heat Flow Prescribed at the Base". Course Conclusion Paper. (Degree in Mechanical Engineering) - Volta Redonda University Center, Oswaldo Aranha Foundation. Advisor: Élcio Nogueira, 2015. (in Portuguese)

7. Moreira, José R. "Processos de Transferência de Calor". USP, set/2012

8. Novais, Ariane Silva; Comitre, Roberta Duarte Ferreira Chagas. "Thermal Performance of HeatFlowed Electric Motors Prescript On The Rectangular Flip Bases". Completion of course work; (Degree in Mechanical Engineering) - Volta Redonda University Center, Oswaldo Aranha Foundation; Advisor: Élcio Nogueira, 2014. (in Portuguese)

9. Novais, Ariane; Chagas, R. D. F.; Nogueira, ÉLCIO. "Theoretical Analysis of Thermal Performance of Finned Electric Induction Motors". Cadernos UniFOA (Online), v. IX, p. 19-34, 2014. (in Portuguese)

10. Ordenes M.; Lambert R.; Güths, S. "Surrounding Heat Transfer in Building". Departamento de 
Engenharia Civil - Universidade Federal de Santa Catarina, Florianópolis, Brazil, 2008.

11. Santos, Rafael Simões. "Three-phase Induction Motor Starting Disorders". Viçosa, Brazil, 2011.

12. Santos, T. A. M. "Thermal Performance Analysis of Finned Electric Motors: Bidimensional Solution in Rectangular Fin with Prescription Based Temperature". Completion of course work. (Degree in Mechanical Engineering) - Oswaldo Aranha University Center - Volta Redonda. Advisor: Élcio Nogueira, 2017. (in Portuguese)

13. Voigdlener, Thiago. "Flow and Heat Transfer in Induction Electric Motors". University of Santa Catarina, Florianópolis, Brazil, 2004. 